\title{
Primates, Computation, and the Path to Language
}

\author{
Reply to Comments on "Towards a Computational Comparative \\ Neuroprimatology: Framing the Language-Ready Brain” \\ Michael A. Arbib
}

Computer Science, Neuroscience and the ABLE Project (Action, Brain, Language, Evolution)

University of Southern California, Los Angeles, CA 90089, USA

Keywords: Apes; Brain Modeling; Comprehension; Computational Comparative Neuroprimatology; Computational Neurolinguistics; Construction Grammars; Conversation; Dementia; Dorsal Stream; Grammaticalization; Imitation; Mosaic Evolution; Neurolinguistics; Neuroprimatology; Niche Construction; Ontogeny of Gesture; Pantomime; Phonology; Primatology; Protosign; Protospeech; Turn-Taking; Ventral Stream

\section{Datasets and Models}

The target article (Arbib, 2015), henceforth TA, had as its main title Towards a Computational Comparative Neuroprimatology. This unpacks into three claims:

- Comparative Primatology: If one wishes to understand the behavior of any one primate species (whether monkey, ape or human - TA did not discuss, e.g., lemurs but that study could well be of interest), one will gain new insight by comparing behaviors across species, sharpening one's analysis of one class of behaviors by analyzing similarities and differences between two or more species.

- Comparative Neuroprimatology: This adds the challenge of comparing brains across primate species and seeking to relate comparisons of brain and of behavior.

- Computational Comparative Neuroprimatology: Here the aim is to go beyond informal analysis of brainbehavior relations, using computational modeling to assess the contributions of specific brain regions or neural circuitry to a class of behaviors in one species, proceeding thence to offer a more detailed analysis of how neural similarities/differences across species can enrich our understanding of behavioral similarities/differences

We may see this as an important subclass of computational neuroethology, providing a particular perspective on ethology, the study of animal behavior more generally. Much current neuroscience uses genetically modified mice to explore neural mechanisms, so future work may increasingly consider mice as "honorary primates" - but this observation points up a major lacuna in the TA and the commentaries, namely the role of genetics. However, we do extend the study "upwards" from studying the brain and body of a single individual to the study of social interactions.

The subtitle Framing the Language-Ready Brain offers an interlocking set of case studies to exemplify computational comparative neuroprimatology. It combined

- A summary of prior work on the Mirror System Hypothesis (MSH) for the evolution of the human languageready brain, based on comparison of monkey, ape and human praxis and communication - spanning from Arbib 
and Rizzolatti (1997) and Rizzolatti and Arbib (1998) to Arbib (2012) (How the Brain Got Language henceforth HBGL) via many intermediate studies - with

- An account of a true exercise in computational comparative neuroprimatology, namely using modeling of how the macaque brain subserves visuo-manual coordination to ground a model of how chimpanzee brains could support the acquisition of novel gestures, and

- an attempt to better characterize "what it is that evolved" through (computational) neurolinguistics.

None of the commentaries address the general program of computational comparative neuroprimatology; they are divided between those that assess aspects of (non-computational) comparative neuroprimatology, and those that focus on aspects of the human capacity for language in ways that enrich our understanding of the language-ready brain rather than its evolutionary or primatological setting. And some point to relevant modeling of human processing or related efforts in artificial intelligence. To put this in perspective, consider Table 1 (the datasets related to commentaries) and Table 2 (the computational models related to commentaries).

\section{Table 1. The datasets related to commentaries}

This is not limited to the datasets explicitly discussed in the commentaries but also includes data implicit in the commentary itself that inform the arguments put forward in the commentary. (Here and elsewhere, An author's name in boldface refers to his or her commentary.)

\begin{tabular}{|c|c|}
\hline \multicolumn{2}{|l|}{ Monkeys } \\
\hline Bornkessel-Schlesewsky et al & $\begin{array}{l}\text { Neurophysiology of the macaque auditory system; vocalization sequences } \\
\text { in Campbell monkeys }\end{array}$ \\
\hline Coudé & Neurophysiology of premotor correlates of conditioned vocalization \\
\hline $\begin{array}{l}\text { Garrod \& Pickering; } \\
\text { Moulin-Frier \& Verschure }\end{array}$ & Turn-taking in marmoset vocalization \\
\hline Iriki & Monkey neurophysiology \\
\hline \multicolumn{2}{|l|}{ Apes } \\
\hline Liebal & Gestural repertoires in great apes \\
\hline Russon & Imitation and pantomime in great apes, primarily orangutans. \\
\hline \multicolumn{2}{|c|}{ Comparison of Monkeys, Apes and Humans } \\
\hline Hecht & $\begin{array}{l}\text { Comparative diffusion tensor imaging of macaques, chimpanzees and } \\
\text { humans; comparative diffusion tensor imaging of humans before and after } \\
\text { training in stone knapping (neural component of experimental archeology } \\
\text { with Stout Stout) }\end{array}$ \\
\hline \multicolumn{2}{|r|}{ e } \\
\hline Colagé & Brain imaging of neural correlates of reading \\
\hline Brouwer \& Crocker & $\begin{array}{l}\text { Evoked response potentials as indicators of timing and coarse localization } \\
\text { of neurolinguistic processes }\end{array}$ \\
\hline Garrod \& Pickering & Neuroimaging studies of neural oscillations in auditory cortex \\
\hline Hawkins & Psycholinguistic data relating language performance and of grammars \\
\hline Heine & $\begin{array}{l}\text { Comparing grammars of diverse human languages as a basis for theories of } \\
\text { grammaticalization }\end{array}$ \\
\hline Knoeferle & $\begin{array}{l}\text { Psycholinguistic studies linking hierarchical structures in vision and } \\
\text { language }\end{array}$ \\
\hline Wray & $\begin{array}{l}\text { Observation of "conversations" between a person with dementia and a } \\
\text { family carer }\end{array}$ \\
\hline \multicolumn{2}{|c|}{ Comparison of Humans and Protohumans } \\
\hline Stout & Archeology (stone tools); experimental archeology (implicit; see Hecht) \\
\hline
\end{tabular}


Much work needs to be done to develop databases and attendant neuroinformatics tools to systematize, search and compare the diverse forms of data exemplified above. In July of 2011, I hosted a Workshop on "Action, Language and Neuroinformatics" to address this issue. The necessary developments are charted in the papers in a special issue of the journal Neuroinformatics, with an integrative summary provided in the final paper (Arbib, Bonaiuto, et al., 2014). A prior effort developed the Neurohomology Database (NHDB) to link data on brain mechanisms for action (macaque, human) and language (human) with specific concern for data relevant to the evolution of the language-ready brain (Arbib \& Bota, 2003) but, alas, the database is now defunct, and I would like to see the development of NHDB Redux to systematize the relevant data. Subsequent efforts include the Gesture and Behavior Database (GBDB; http://gbdb.usc.edu/gbdb/) which awaits the insertion of data on ape gesture and behavior.

Table 2: Models related to commentaries General Frameworks (Non-computational)

\begin{tabular}{|c|c|}
\hline Bornkessel-Schlesewsky et al & $\begin{array}{l}\text { Informal discussion of ubiquity of "forward" (predictive) models in diverse } \\
\text { neural systems. }\end{array}$ \\
\hline Iriki; Stout & Niche construction \\
\hline Stout & Evolutionary theory as a general framework \\
\hline \multicolumn{2}{|l|}{ Monkeys } \\
\hline $\begin{array}{l}\text { Garrod \& Pickering; } \\
\text { Moulin-Frier \& Verschure }\end{array}$ & $\begin{array}{l}\text { A computational model for vocal exchange dynamics and their } \\
\text { development in marmoset monkeys }\end{array}$ \\
\hline \multicolumn{2}{|l|}{ Apes } \\
\hline Hecht & The ontogenetic ritualization model presented in TA. \\
\hline \multicolumn{2}{|l|}{ Humans: Neural } \\
\hline Brouwer \& Crocker & $\begin{array}{l}\text { The (informal) extended Argument Dependency Model (eADM) and a } \\
\text { recurrent neural network model, with anatomically localized subsystems, of } \\
\text { sentence comprehension }\end{array}$ \\
\hline \multicolumn{2}{|l|}{ Humans: Non-Neural } \\
\hline Hawkins & $\begin{array}{l}\text { Analysis of sets of grammatical rules in relation to efficiency of language } \\
\text { processing }\end{array}$ \\
\hline Schwartz et al & $\begin{array}{l}\text { COSMO, a sensori-motor model for speech communication in which the } \\
\text { listener may exploit motor knowledge associated with production of a } \\
\text { sound similar to the acoustic stimulus to be recognized; interaction games } \\
\text { between COSMO agents }\end{array}$ \\
\hline Wray & $\begin{array}{l}\text { Informal discussion of a possible extension of the TCG model of language } \\
\text { comprehension and production }\end{array}$ \\
\hline \multicolumn{2}{|l|}{ Robots } \\
\hline Moulin-Frier \& Verschure & $\begin{array}{l}\text { Construction of communicative humanoid robots able to realize complex, } \\
\text { open-ended and dynamic dyadic tasks with a human; a computational } \\
\text { model where turn-taking behavior emerges in agent populations }\end{array}$ \\
\hline
\end{tabular}

None of the commentaries offer us examples of modeling efforts that explicitly compare models of brain mechanisms in different species. The general challenge to be addressed, then, is how such models may be generated and compared, although Figure 4 and the attendant text (Section 1.5) of TA do suggest how to use models of monkey brains to ground modeling of ape brains and human brains within an evolutionary perspective. Indeed, more effort is needed on a related problem: Even when working with the same species, how does one compare two or more models of related phenomena - not simply to judge one better than another, but rather to determine how to combine the best features of the models to expand explanatory power while reducing unwarranted assumptions? The Brain Operation Database (BODB; http://bodb.usc.edu/bodb/) offers an environment for linking descriptions of 
brain models to summaries of the empirical data used to design and test them and includes a simple benchmarking tool for model comparison (Arbib, Plangprasopchok, Bonaiuto, \& Schuler, 2014), but more research is needed to build on this foundation.

With this, I turn to the commentaries. My aim is to express my appreciation of each one while trying to integrate them into an overarching framework for approaching the Language-Ready Brain within an expanding framework for Computational Comparative Neuroprimatology.

\section{Niche Construction}

Stout (Stout, 2016) reminds us of the emergence of an "extended" evolutionary synthesis which sees organisms as active agents in evolution. with inheritance involving more than just genes. A key notion here is niche construction (Laland, Odling-Smee, \& Feldman, 2000). Though discussed in HBGL, it deserves more attention (Sinha, 2013). Stout points out that our quest to compare monkey, ape and human can be enriched by cognitive archeology (Davidson, 2010) as we seek to infer behaviors of our (proto)human ancestors from the archeological record, then posit the cognitive capacities needed for these behaviors and seek to relate these to endocasts, the traces of brain shape left in fossil skulls (Wilkins \& Wakefield, 1995). Stout has pioneered the use of "experimental archeology," for example teaching humans techniques for making stone tools, carrying out brain imaging to see what connections are changed in the process, and using this to develop hypotheses about how new technologies might have favored changes in brains which aided the development of such technologies: In work with Stout, Hecht et al. (2015) showed that "acquisition of Paleolithic toolmaking abilities involves structural remodeling to inferior frontoparietal regions."

Stout advocates a "technological pedagogy" hypothesis for the transition from complex imitation to intentional communication (Stout \& Chaminade, 2012). A similar point was made in HBGL (p.193): "All humans certainly learn by observation, but this can lead to complex imitation, not only simple imitation, and humans can benefit from the explicit instruction that only humans can provide."

Reinforcing the importance of understanding niche construction, Colagé (Colagé, 2016) notes that learning to read changes the functional and anatomical connections of and with speech areas in the superior temporal, inferior parietal, and inferior frontal regions. Indeed, Dehaene and Cohen (2007) speak of "cultural recycling of cortical maps" while Dehaene et al. (2010) explore "how learning to read changes the cortical networks for vision and language." Colagé ties this discussion to my attempt to roles of ventral and dorsal pathways in language processing (TA, Sec. 4). Since certain changes in the human brain adaptive for reading occur at the ontogenetic time-scale within a niche constructed by cultural evolution, he supports the possibility that analogous processes (cultural and ontogenetic) formed "new brain functional and anatomical networks able to support full-blown spoken language as distinct from forms of protolanguages possibly in use among early groups of $H$. sapiens." I agree, and so the task in developing the implications of MSH for neurolinguistics (going far beyond the sketch in TA, Sec. 4.1) is to better understand what aspects distinguish the human brain from ape or monkey brains (and note the discussion of different species below) as a basis for assessing what makes only the human brain language-ready while further assessing how acquisition of a language changes the brain's structure and not just its function. 
Iriki (Iriki, 2016) sees TA as claiming that "it is the interaction of the newborn with its care takers ... that brings the brain mechanism subserving language faculty to really mature to its final completion, [leading us to develop] ... computational theories and mechanisms of Evo-Devo-Eco interactions for language acquisition in human brains." $\mathrm{He}$ notes that "songbirds manifest vocal learning and communication capabilities through brain structures/connections remarkably different of those of human language brain systems, yet under surprisingly similar principles" (Fitch \& Jarvis, 2013), yet human language has enormous capacity far exceeding that of the communication systems of other species. Thus Iriki stresses the importance of studying the general properties of the "primate brain" as a basis for understanding what is the shared substrate that laid the basis for the particular features of human brain that made it "language-ready," setting the stage for construction of the "language niche" in which today's children can master the use of language in a few years of "dyadic brain-to-brain interaction between infants and caretakers (mothers in particular, and other family and social members)" - a process whose challenges for computational comparative neuroprimatology were exemplified in the monkey-inspired model of ape ontogenetic ritualization (Arbib, Ganesh, \& Gasser, 2014) presented in TA, Sec. 2.2.2. My only complaint about Iriki's commentary is that he does not cite his own highly relevant work, including discussions of "triadic (ecological, neural, cognitive) niche construction: a scenario of human brain evolution extrapolating tool use and language from the control of reaching actions" (Iriki \& Taoka, 2012), nor a wide range of studies on the macaque ranging from tool use to vocalization and social interaction (Arbib \& Iriki, 2013; Hihara, Yamada, Iriki, \& Okanoya, 2003; Iriki, 2006; Ishibashi et al., 2002; Kumashiro et al., 2003; Quallo et al., 2009; Yoshida, Saito, Iriki, \& Isoda, 2011) and recent work on marmosets (Kato et al., 2014; Yamazaki et al., 2011).

\section{Learning from the Great Apes}

A crucial feature of MSH is to use a comparison of both imitation and communication in monkey, ape and human to suggest that LCA-c, unlike LCA-m, had a somewhat flexible system of innovation of manual gestures but still had no vocal learning (Arbib, Liebal, \& Pika, 2008), and that while LCA-m and LCA-c both had manual dexterity and skill learning, only LCA-c had what I call "simple imitation." The path from LCA-c to Homo sapiens was then argued to involve the emergence of brain mechanisms supporting complex imitation, then pantomime which in turn opened up semantics with conventionalization yielding protosign which in turn provided essential scaffolding for the emergence of protospeech and vocal learning. Russon (Russon, 2016) argues, perhaps overgenerously, for greater capacities of imitation and pantomime in the great apes, while Liebal (Liebal, 2016) reminds us (as TA does) that the ontogenetic realization modeled in TA can only account for part of the ape gestural repertoire. Hecht (Hecht, 2016) offers a comparative analysis of cortical connectivity in macaques, chimpanzees and humans that may support comparative modeling to pursue fresh insights into the co-evolution of brain, skill and imitation.

\subsection{Great Ape Imitation and Pantomime}

Russon claims that great apes are capable of all three of complex imitation, pantomime and protosign whereas TA portrays these abilities as unique to the human lineage. Indeed, she offers an impressive set of examples (from gorillas and, primarily, from orangutans) that needs careful analysis. My prime concern here is that perhaps Russon 
uses these three terms more generously than I do, and we thus need a concerted effort to more formally characterize the differences between the capacities revealed in Russon's examples and those I attribute to humans. After all, if we shrink the differences too far, we would expect apes to master syntax, which they do not do.

As far as pantomime is concerned, my impression (I have not read all the cited papers) is that Russon uses the term for isolated examples in which a gestural structure may come to be recognized by others as an index for a behavior it more or less resembles (much as in the ontogenetic ritualization of TA Sec.2.2), whereas in MSH "pantomime" is a communally recognized strategy in which, on an opportunistic basis, an individual can generate a novel intransitive behavior to convey something associated with a related behavior and other individuals, being aware of the general strategy, will attempt to extract the meaning of this (to them) recognizably communicative act. The distinction here is between "pantomime as a readily deployable strategy" and "isolated behaviors we might label as pantomimes." The former requires a great deal of neural machinery beyond that posited in the model of TA Sec.2.2. While MSH places the evolution of this machinery on the path from LCA-c to Homo sapiens, I agree with Russon on the value of comparative primatology in better assessing where it might have emerged in the primate evolutionary tree (and see the discussion of Mosaic Evolution below) - but I would still insist on the importance of adding a "computational neuro" component to the investigation. Certainly, the examples cited by Russon themselves offer challenges to the computational modeler.

Russon suggests that two sign-language trained great apes, Kanzi and Washoe, have used protosigns. This is somewhat misleading. Apes do not learn a language (which includes the open-ended use of a grammar to share complex new meanings); they learn to use a set of signs -- and humans originated the signs. What, then, yields a species that generates its own protosign? Perhaps the key here is ratcheting (Tennie, Call, \& Tomasello, 2009). Apes may come up with isolated pantomime-like examples but cannot accumulate a system. Coming up with an understanding of how the brains of a group could support ratcheting as a key mechanism for the evolution of cumulative culture is a crucial challenge. Moulin-Frier \& Verschure (Moulin-Frier \& Verschure, 2016) discuss studies of interacting agents (artificial intelligence programs, rather than animals with brains) which do "ratchet up," but the effect is programmed into the model, rather than assessed as a challenge in evolutionary neuroscience.

\subsection{The Ontogeny of Great Ape Gesture}

As noted in TA Sec.2.2, some authors argue that ape gestures are either "species typical" or produced by only a single individual. However, a few group-specific gestures have been observed in ape populations, suggesting a role for social learning. Tomasello and Call (1997) proposed ontogenetic ritualization as a means whereby (some) ape gestures could emerge, and it is this that we modeled. Liebal expands the relevant database, discussing current evidence from primate gesture research with regard to the different mechanisms proposed for gesture acquisition. However, I find her claim that "there seems little disagreement in regard to the negligible role of imitation for gesture acquisition" puzzling, and wonder whether it follows from the difficulty of conducting longitudinal studies (a problem which has also bedeviled claims for ontogenetic ritualization). My puzzlement follows from the wellestablished view that apes do learn skills by imitation (Byrne \& Russon, 1998). However, Liebal reports that individual repertoires of infants show little overlap with those of their mothers, while all infants (across different groups in different settings) shared a similar set of gesture types, as did mothers . "Because of this pronounced 
overlap of gestural repertoires within each of these two age groups ... but not between them, it seems unlikely that infants acquire their gestures by imitating their mothers. One possible conclusion is that gestures are largely innate... [A]n alternative explanation for the overlapping individual repertoires within a particular age group is that these individuals might use similar gestures because they need to accomplish similar goals - which might differ from those of other age groups."

Noting that there is flexible usage of more than one gesture for one specific goal, Liebal asks whether it is necessary to develop a separate model for the ontogenetic ritualization of each gesture. I don't think so. Although the model of TA Sec.2.2 has not been run on diverse scenarios, I speculate that only a single set of neural mechanisms need be involved. Maybe different contexts set the stage for the emergence of different gestures for what we (mistakenly?) characterize as instances of the same action. Anyway, I reiterate the importance of follow up research on the paradigm of taking a macaque-inspired neural model and seeing what must be added to yield an "ape-like" model of some feature of dyadic interaction.

Liebal also asks whether tactile gestures are expected to be ritualized differently or even faster than visual gestures, because they might require fewer steps than the "6-step model" for beckoning, but I stress that the model is not a "6-step model." Rather it is a single learning model for which the learning across multiple trials could be described via 6 stages - but these are for convenience of description, not reflective of different forms of neural processing. However, I agree completely with Liebal's conclusion that gesture acquisition cannot be explained by ontogenetic ritualization alone, and indeed the search for other mechanisms is a target of current modeling.

\subsection{Dorsal and Ventral Streams in Comparative Perspective}

Early conceptualizations of the two-streams hypothesis focused on similarities between monkey and human brain organization. Hecht outlines how differences in connectivity can now be identified with diffusion tensor imaging which reveals elaboration in the human of dorsal connections relevant for language via the arcuate fasciculus (Rilling et al., 2008). Since, on a general, theoretical level, "tight inter-relationships seem probable between the organization of white matter connections and the type of processing carried out by gray matter regions," Hecht and her colleagues have proposed that "adaptations to action observation networks may be related to the evolution of social learning." For Hecht, the preponderance of ventral temporal-frontal circuitry observed in monkeys and chimpanzees relative to humans might correspond to their bias toward reproducing mainly action goals. In contrast, humans' elaboration of dorsal, temporal-parietal and parietal-frontal circuitry might support increased bias toward reproducing specific methods. In particular, the extension of SLFIII into BA45 might provide a point of greater intersection between dorsal and ventral streams, supporting increased integration of hierarchical conceptualizations of action goals with concrete kinematic, proprioceptive, and spatial details - a function which would be increasingly important during the evolution of behaviors where hierarchical action goals are causally dependent on kinematics, as they are in stone toolmaking (and see the earlier comments from Stout).

Importantly for our computational efforts, Hecht comments that these findings agree with the suggestion (Arbib, Ganesh, et al., 2014; Gasser, Cartmill, \& Arbib, 2014) that increased proprioceptive input could facilitate the ontogenetic ritualization of manual gestures. Noting that social learning and cultural evolution have been modeled at the population level, Hecht poses the challenge of creating a population of MNS models (cf. TA, Secs.2.1 and 2.2) 
to examine how variation in circuit organization plays out across interacting individuals. She asks: What happens when one alters the weight or organization of connections between nodes? Do resultant processing changes parallel what we see in experimental comparative neuroscience? Would it be possible to create a population of MNS models and examine how variation in circuit organization plays out across interacting individuals?

\subsection{Mosaic Evolution}

Since much of the evidence for "complex imitation" and "pantomime" in great apes cited by Russon is from orangutans, she views these abilities as representing LCA-ga, the last common ancestor of all great apes and humans (ca 13-18 Ma), not chimpanzees and humans (ca 6-7 Ma). Indeed, different ape species exhibit different suites of capacities relevant to evolution of the language-ready brain, so a trait shared by one species with humans may occur in LCA-c, whether or not it occurs in LCA-ga. We need to relate behavioral differences among apes to differences in their brains, and that seems (politically) increasingly hard to do. We are left with "mosaic evolution" and the challenge of understanding why the same feature of the phenotype appear twice. Is it "close" in the genetic structure and thus awaiting similar triggers for its independent expression?

Russon speaks of MSH as valuable but "in need of revision." Indeed, MSH is not a static structure but a framework for continuing research. However, Russon's data do not suggest revision of MSH so much as the need for a finer grained analysis of different apes in terms of pushing inferences on the various forms of LCA-x as a basis for an account of "mosaic evolution." Earlier, I noted that Iriki's earlier studies of macaque brain and behavior are now complemented by recent work on marmosets. This points us to the understanding that comparative neuroprimatology must not only be conducted at the coarse scale of monkey versus ape versus human but also at the finer scale of assessing similarities and differences linking brain and behavior between different species of monkeys and apes.

Hecht offers the one commentary to explicitly compare brain connectivity in monkeys (specifically macaques), apes (specifically chimpanzees) and humans. She notes that macaques do not have language, nor other likely pre- or co-adaptations to language, such as complex imitation and tool use. By contrast, tool use is observed in one group of cebus monkeys (Visalberghi et al., 2007) Visalberghi, Savage-Rumbaugh, and Fragaszy (1995) early compared performance in a tool-using task by chimpanzees, bonobos, an orangutan and capuchin (cebus) monkeys, pointing again to the need to distinguish different species of monkeys and apes in pursuing comparative primatology.

TA (Sec.1.6) lists recognizing intentions, symbolization and conventionalization, parity of symbols between producer and receiver; and recall and imagination "beyond the here and now.". Croft (Croft, 2016) stresses that these traits are at least as important in the evolutionary emergence of language as pantomime. Moreover, there "has to be a motivation for our ancestors to engage in pantomime and hence to act as a selectional pressure for the evolutionary emergence of pantomime... It would be useful to spell out how mirror neurons might lead to the evolution of common ground, recognition of intention, helping and other elements of joint action that form the basis of coordination between agents and conventional signs. I can only agree, seeing this as setting important challenges for future work. I only add that mirror neurons alone cannot do all this - we have to understand the evolution of their interaction with systems "beyond the mirror." In any case, we do see the need to extend our modeling to include not only recognizing of the goal of another's action but also the invocation of a value system that judges the goal. 


\section{The Claim That Protosign Scaffolds Protospeech Remains}

\section{Controversial}

Noting that one key argument of MSH is that the establishment of "open semantics" in the manual modality (i.e. protosign) provided the adaptive pressure favoring enhanced vocal control and protospeech, Stout offers the alternative hypothesis that an evolving technological niche would have been sufficient to favor the emergence of human multimodal communication, for example to exploit complementary strengths of vocal and manual modalities. Similarly, Bornkessel-Schlesewsky et al (Bornkessel-Schlesewsky, Alday, \& Schlesewsky, 2016) suggest that, "given the ubiquity of internal models across modalities and the resulting availability of combinatory mechanisms to various brain systems, it is not clear why combinatorics in the manual-visual system need have been primary in leading to protolanguage - and the evolution of speech and language in the auditory domain." My concern is that neither commentary addresses the fact that in all nonhuman primates, the complexity and adaptability of manual skill far outweighs those of vocal production. They fail to offer an account of the evolutionary pressure that would yield a sufficiently flexible system for vocal control and learning to replace the MSH hypothesis that it was the opening of semantics by protosign that provided scaffolding for protospeech and the attendant vocal control.

The discussion of internal models has a long history (Arbib, 1972; Craik, 1943; Gregory, 1969; Minsky, 1965) and forward models were discussed in the first publication on MSH (Arbib \& Rizzolatti, 1997, Neural expectations: a possible evolutionary path from manual skills to language). The appeal by Bornkessel-Schlesewsky et al to "the ubiquity of internal models" has little explanatory force - just as an appeal to the "ubiquity of vision" would do nothing to explain the evolution of the gross differences between frog and human visual systems. BornkesselSchlesewsky et al note that "even in macaques and thereby likely in the last common ancestor of macaque, chimpanzee and human (LCA-m), the auditory system, and specifically the ventral auditory stream, demonstrably supports auditory object recognition" but this ignores the fact that these creatures lack the ability to voluntarily control vocal production and freely learn new vocal patterns, and have limited auditory memory (Fritz, Mishkin, \& Saunders, 2005). Nonetheless, we do need further investigation of the question of whether mimesis was "panmodal" (Donald, 1997, 1998) or needed one modality to scaffold the broader capability (as suggested by the ape's ability to imitate manual but not vocal actions). Bornkessel-Schlesewsky et al cite Collier, Bickel, van Schaik, Manser, and Townsend (2014) to assert that "Campbell monkeys employ vocalization sequences which encode at least rudimentary compositional semantics and thus require some level of symbolic encoding," but this is limited to an innate use of an "-oo" affix to modify two calls, and thus does not qualify as a step towards a flexible grammar. (Cf. my comment on Arnold and Zuberbühler (2006a, 2006b) on pp.75-76 of HBGL.) Nonetheless, it might provide one "tile" in the approach to mosaic evolution called for above.

Coudé (Coudé, 2016) returns to an earlier critique (Fogassi, Coudé, \& Ferrari, 2013) of a possible overemphasis on hand over voice in MSH, recalling a study (Coudé et al., 2011) in which recording from ventral premotor cortex (PMv) of macaques trained to emit vocalizations (i.e. coo-calls) showed that the rostro-lateral part of PMv contains neurons that fire during conditioned vocalization. "The behavioral data ... highlighted that vocalizing on command is achievable in macaques. It also showed that it remains a limited ability." As one of the 
few behavioral examples of vocal control in monkeys reported in the literature, Coudé cites the Lombard effect in which vocalizing monkeys can raise the amplitude of their calls in response to masking ambient noise to increase the signal-to-noise ratio. Fogassi et al. (2013) argued that "from the standpoint of evolution, macaque data suggest a timescale for the emergence of vocal control such that some evolutionary pressure must have come into play well before the use of protosigns (i.e. communication based on conventionalized manual gestures) developed". On this view, the vocalization control circuitry in the monkey (LCA-m) was a building block for what would later become the controlled utterances of protospeech. Perhaps Coudé would agree with my earlier response (Arbib, 2013, p.289) to Fogassi et al. (2013): "The connections revealed by their study reflect massive conditioning of monkeys in the laboratory - brains have many connections which did not evolve for a specific function but rather "failed to be pruned" and so can be exploited only by massive training. For me this militates against the view that protospeech did not need scaffolding from protosign, but does indicate pathways presumably present in LAC-m whose massive strengthening in post-LAC-c human evolution could have come to support articulatory control adequate for protospeech."

\section{From Emerging Grammars to Grammaticalization}

\subsection{Protolanguage versus Language}

Following Alison Wray, I argued that much of early protolanguages was constituted by "holophrases", and that some such utterances were eventually broken down in such a way that formerly meaningless parts would be assigned meaning, leading to the identification of "slots" or roles in a construction. This in turn would allow for recombination of units and the emergence of a combinatory sign system typical of modern human language. Croft comments that: "In the auditory/articulatory modality, this hypothesized process is actually extremely rare in modern human language. Arbib (and Wray before him) looks to holophrases in child language acquisition. But holophrases in acquisition are single words use to convey an utterance-level meanings (e.g. towel to accompany using a towel to clean up a spill).” There are two problems with this critique:

1) In MSH, fractionation of pantomime (prior to the emergence of a fully capable articulatory modality) provides a key element of the ability of protosign to scaffold protospeech: the ability to mobilize increasingly conventionalized manual gestures for communication provides an evolutionary pressure for extending vocal control to further exploit this capability. Indeed, Croft further comments that "a decompositional theory might makes more sense for gestural signs, since they are iconic to a great extent." Indeed, HBGL, pp.302-304, offers an explicit example from the emergence of Nicaraguan Sign Language. Returning to the evolutionary time scale, Croft further argues that "something close to a modern sign language, that is, a combinatory gestural sign system, would have to be hypothesized to emerge before the transition to the auditory/articulatory modality." MSH "almost" asserts that the key difference being that a protosign system adequate to scaffold protosign need have only a limited lexicon and very few constructions relative to a modern human (signed or spoken) language.

2) In the context of a modern language, the child is perforce learning words, not protowords - but in early use of a phrase, the separable use of the words in a string may not yet be available. 
In any case, the debate over the nature of protolanguage is very much an open one (Arbib \& Bickerton, 2010).

\subsection{Phonology}

Schwartz et al (Schwartz, M.-L., Bessiere, Diard, \& Moulin-Frier, 2016) suggest that "If the mirror system paved the way for a 'language-ready brain', this should include a 'phonology-ready brain'.” In fact, HBGL (pp.269271) does suggest how complex imitation, in supporting the type of fractionation that led from "holophrases" to "words" could also break out and regularize the crystallization of the diverse patterns of pantomime or sound into composites of a more restricted class of syllables or phonemes (or, in the case of signed languages, combinations of basic start and end locations, hand shapes and movement types). In addition, pp.313-314 discuss the emergence of phonology in Al-Sayyid Bedouin sign language (Sandler, Aronoff, Meir, \& Padden, 2011).

They note that TA proposes that speech can be recognized and understood by "general mechanisms which need not involve the mirror system strongly", and that the mirror system would just complement such general mechanisms (Moulin-Frier \& Arbib, 2013). They outline COSMO, a sensori-motor model for speech communication, associating general auditory processing and specific mirror mechanisms by which the listener may exploit motor knowledge associated to the way he/she would produce a sound similar to the acoustic stimulus to be recognized. This Bayesian model assumes that the motor actions by which speech is communicated to a listener as well as their auditory forms are fully internalized inside an individual's brain. This may be consistent with the finding that words can often be recognized without access to a motor representation; though the latter may be crucial in interpreting noisy or degraded input. However, their discussion seems to overlook evidence that people can recognize speech in a foreign accent, where the motor program for generating a word differs from that of the listener. And no attempt is made to reconcile Figure 1 of Schwartz et al with Fig.15 of TA (from Moulin-Frier \& Arbib, 2013) which attempts to integrate possible roles of mirror neurons within a view of the role in speech comprehension of the auditory dorsal and ventral streams.

\subsection{Grammaticalization}

Heine (Heine, 2016) focuses on grammaticalization (TA, Sec.3.4), a historical process whereby new constructions emerge. The database for such efforts requires written records and thus extends back at most a few thousand years so we are past the period of evolution of the language-ready brain. Rather, communities are finding new ways to express and share their thoughts. Heine suggests that Wray-Arbib model of holophrase fractionation and construction formation can be related to the mechanism of context-induced reinterpretation (Heine, Claudi, \& Hünnemeyer, 1991) which has been shown to be one of the main driving forces in lexical and grammatical change in modern languages, giving rise to new linguistic units and grammatical categories. Examples include the transition from lexical forms, such as verbs, to grammatical forms, such as tense markers, and ways that words can combine to form more complex words or phrases. All this contributes to our understanding of how linguistic complexity of the kind observed in modern languages is likely to have evolved.

Despite this, Heine has a warning for us: "Work on the reconstruction of grammatical categories suggests that linguistic change is essentially gradual rather than abrupt, and there is no compelling evidence to suggest that this was drastically different in the earliest development of languages. [This is an example of "uniformitarianism.] 
Accordingly, the assumption that in this development there was a distinct stage of a protolanguage or of protolanguages must be taken with care." However, one needs a critical mass of words and constructions to get grammaticalization going. "Protolanguage" refers to the early stages in the emergence of human language when the "lexicon" of protowords and the set of constructions were both very small indeed. Within the context of comparative neuroprimatology I would see "uniformitarianism" rather differently. One challenge is to determine what neural processes are necessary to get protolanguages started in a community and test the hypothesis that these processes are adequate to support processes of change, such as grammaticalization, that operate in communities that already have a critical mass in their lexicon and constructions. A complementary challenge is to understand where the corresponding neural processes fall short in non-human primates. The model of TA Sec.2.2 is a step in this direction, and MSH suggests that complex imitation has a special role to play. However, as Russon shows, the definition of complex imitation needs to be refined - and neural models of imitation are still impoverished (but see Demiris, Aziz-Zadeh, \& Bonaiuto, 2014; Oztop, Kawato, \& Arbib, 2013).

Hawkins (Hawkins, 2016) offers a critique of the Chomskian view that a rich innate Universal Grammar guides learning (see also Arbib, 2007) and complements Heine's concern with grammaticalization by stressing that "many grammatical properties that we find in the world's languages today could not have been present in the language of the first Homo sapiens because they are known to have evolved from less complex earlier stages." Hawkins's own critical research addition is to probe how constraints of language processing and efficiency affect the evolution of grammars. The crucial notion is that grammaticalization does not produce new constructions willy-nilly alternatives may compete to fill a new "expressive niche," and those may win that are simpler to process within the framework created by prior constructions. "Matching sets of data from performance and grammars show that even subtle aspects of syntax, of the kind earlier attributed to an innate Universal Grammar, can emerge from earlier pregrammatical stages."

\subsection{Construction Grammars in Perspective}

Knoeferle (Knoeferle, 2016) represents researchers using the Visual World Paradigm to chart how people comprehend sentences when those sentences are linked to the exploration of a visual scene, so that eye movements can be related to the process of comprehension (or production). This addresses in part the question: "in language processing, how precisely does compositional structure and meaning gleaned from speech interact with structure and meaning gleaned from the visual scene?" This approach also motivated Template Construction Grammar (TCG) which was first developed to address the description of visual scenes. There was no claim that scene description is the primary use of language - rather our notion was that this task would provide a bridge to a neurolinguistics which could exploit our knowledge of the neuroscience of vision. For Knoeferle, a key question is then: "How do different grammar and information-theoretic frameworks as well as computational models compare in modeling this mapping?" Steels (Steels, 2016) reminds us that construction grammarians argue that grammatical constructions add novel meaning to the meaning already supplied by words through the lexicon, with a gradation between lexical constructions, idiomatic constructions, and more generic grammatical constructions. Croft stresses that Construction Grammar is a family of related theories of syntactic structure and its relation to semantics. His own Radical Construction Grammar (Croft, 2001) draws on evidence from cross-linguistic universals and variation. TA Sec.1.7 
explicitly mentioned three "flavors" of computational construction grammar in addition to TCG: Dynamic (DCG), Embodied (ECG) and Fluid (FCG) Construction Grammar), and commented: "Each of the four CG frameworks listed above has clear strengths ... [but each] covers only a portion of the mechanisms whose evolution we need to understand if we are ... make rich contact with studies of the interactions within and between brains. We will learn from each of them in future research." To this search for relevant strengths we may add Knoeferle's coordinated interplay account (CIA!) of situated sentence processing (Crocker, Knoeferle, \& Mayberry, 2010; Knoeferle \& Crocker, 2006) and the related modeling discussed by Brouwer and Crocker (Brouwer \& Crocker, 2016) below.

Knoeferle notes, as does TA, that during language evolution (unlike language development), humans did not benefit from observing other language users with a full-blown grammar system in place. Three key differentiating aspects are the linguistic context, the situational context and the time scale of the process. Steels points up some of the shortcomings of TCG in addressing these diverse timescales. He stresses that language is unique because the rules of the system are not fixed, and its vocabulary and constructions can be extended at any time and at will by the speaker, and the listener has to follow suit. He illustrates this by dissecting the attention-grabbing sentence of his commentary's title. He notes that there is usually "competition ... between different ways to express the same meaning but there is also a counterbalancing force of self-organization ensuring that some conventions become and remain dominant ...This makes language a complex adaptive system that is undergoing constant evolution." Here Steels cites, but does not discuss, his own Physics of Life review (Steels, 2011) which reviews his research on interacting robots or computational agents, showing how communicative interaction about a shared environment can support the emergence of a shared lexicon and some constructions. This work gave us the explicit introduction of the semiotic cycle (TA, Fig.2) and involved the development of Fluid Construction Grammar. Our model (TA, Sec.2.2) of how their brains could support the emergence of gestures in interacting chimpanzee was our attempt to bring something of this view into computational comparative neuroprimatology.

Moulin-Frier \& Verschure pick up on the theme of dyadic models illustrated in Fig.2, noting several important studies based on Steels's paradigm of "language games" which show how particular properties of speech and language can self-organize out of repeated dyadic interactions between agents of a population. However, individuals in those models are pre-programmed to interact together in a very-specific way. It is an open question how such motivations to interact, or at least to produce some signals that can then be recruited for communication, originated. They suggest that individuals may be equipped with active exploration mechanisms pushing them to discover how their behavior affects the surrounding world. A related model in the context of rat navigation (computational comparative mammalogy) was introduced by Arbib and Lieblich (1977), cited in a discussion of language evolution (Arbib, 2003), and elaborated in the context of recent findings on reinforcement learning. (Arbib \& Bonaiuto, 2012). Moulin-Frier \& Verschure cite a number of computational models, that show how such active exploration mechanisms can bootstrap discovery of communication systems They suggest that intrinsic motivations to explore could also play a role in the open-ended creation of new protosigns, viewed in TA as a dyadic process of conventionalization (Sec 2.3). The general challenge is this: "How can findings in AI studies of evolutionary computing inform our modeling of brains carrying out related functions, and how can these brain studies be placed in evolutionary perspective?" A related example in brain modeling is the quest to understand how studies of the role 
of hippocampus in rat navigation might inform our understanding of its role in episodic memory, and how this in turn might be related to computational neurolinguistics (O'Keefe, 1996, 2003, 2014).

Steels offers several criticisms of TCG:

1) When speaking you need to decide on the topic of the scene and on the perspective from which this topic is introduced, and to take the listener into account when planning the utterance Indeed, we acknowledge this in HGBL. But these important issues are complementary to TCG, which focuses on the relation between visual and linguistic representations.

2) The representations of semantics, intermediary linguistic structures and grammar will have to become much more sophisticated as well. Steels offers the challenge of representing various phenomena from linguistics. However, the broader question is what happens when we extend semantic relations beyond those explicit in a single visual scene (which may extend over a short time interval). An immediate augmentation of TCG (which we are currently considering) would be to handle questions about the scene and requests/commands such as "Give me some milk," in which we combine a motivational system with a visual system and an action system to frame topics the language is to express. In other words, I see the immediate challenge (which may well require combining features of TCG with those from DCG, ECG and FCG as well as CIA and its refinements - one might speak of CG++) as being able to process simple sentences to address data from psycholinguistics and neurolinguistics using the Visual World Paradigm.

3) "It is not clear whether the cooperation/competition mechanism proposed in the paper is enough to handle the large search spaces, backtracking, or heuristic guidance that is needed for parsing or producing complex utterances." Agreed, but note that the framework for the effort proposed here is that of neuroscience as well as primatology. The issue will be to track new research on the neurobiology of decision making to decide how the cooperation/competition mechanism has been refined, constrained or augmented to avoid the "combinatorial explosion" that also plagues AI efforts. In particular, could it be that the language-ready brain differs from that of other primates in that the evolution of prefrontal cortex supports not only increasing complexity in perception, planning and motor control, but also involves innovations that combat the combinatorial explosion that increasing complexity might otherwise yield?

4) The model "needs to be extended to handle continuously evolving change in language, which implies that individuals must be able to store construction variants, track the level of entrenchment of these variants, and dynamically adapt their own choices as the language changes." Actually, in our early work on language acquisition by a 2 year old child (Hill, 1983), Jane Hill modeled the emergence of new constructions (she called them templates) and then used adjustable weights based on experience to determine how they would enter into the cooperation/competition of language processing. One may note similarities here with MacWhinney's competition model (Bates \& MacWhinney, 1989; MacWhinney, 1987, 2010, 2012). Certainly, building on these insights to develop CG++ (Chang, 2004, provides an ECG-based approach) could well be integrated with the work of the Steels group in framing how language changes as people interact. However, the research program outlined in TA does not aim to replace computational linguistics theories of language processing, acquisition and change so much as to understand the brain mechanisms that make language possible. 
For me, then, the real criticism of the current state of TCG (unvoiced by the commentators) is twofold:

(i) The structure of the model is informed by a general cooperation/competition view of schema processing as a framework for brain theory but falls short as a computational model that addresses neurolinguistic data.

(ii) It is not framed in a way that allows comparison, via an MSH-based view of the brain mechanisms underlying language (TA, Sec.4.1), with neural models of monkey and chimpanzee action and interaction (such as those of TA Sec.2) to adequately contribute to the development of computational comparative neuroprimatology. Current work addresses (i); work on (ii) is currently more conceptual than computational.

With this, we turn to those commentaries that address the views (note plural) on dorsal-ventral perspectives on brain and language presented in TA Sec.4.

\section{Towards a Computational Neurolinguistics}

Within the perspective offered by TA, we may see computational neurolinguistics as defining the target for an account using computational comparative neuroprimatology of the evolution of the language-ready brain. The challenge is to model what evolved (the neurolinguistics) to frame analysis of how it evolved (MSH or its replacements) while bearing in mind Colagé's stricture that, as is the case for reading, the structure of the languageusing brain may depart from the structure of the merely language-ready brain of early humans due to the impact on the modern child of enculturation in a language-rich society.

Unfortunately, none of the commentaries discusses the hypotheses of TA Sec. 4.1, "An MSH-based view of the brain mechanisms underlying language," so it remains a major challenge to assess to what extent these are consistent with emerging attempts to create a computational neurolinguistics. Instead, Brouwer \& Crocker offer a critique of the B\&S model (Bornkessel-Schlesewsky \& Schlesewsky, 2013) of TA Sec.4.2 and argue for an alternative computational neurolinguistic model of sentence comprehension; while Wray uses the study of patients with dementia to offer a novel perspective on TCG.

\subsection{Sentence Comprehension}

Brouwer \& Crocker see the B\&S model of sentence comprehension (i.e., the model of Bornkessel-Schlesewsky \& Schlesewsky, 2013, reviewed in TA Sec.4.2) as a cortical instantiation of the extended Argument Dependency Model (eADM, Bornkessel \& Schlesewsky, 2006). Crucially, eADM explicitly links processing in the dorsal and ventral auditory streams to the N400 and P600 components of Event-Related brain Potentials (ERPs) during sentence comprehension. However, Brouwer, Fitz, and Hoeks (2012) have argued that the model cannot account for the full spectrum of ERP findings for neurolinguistics. Instead, Brouwer \& Crocker assert that their single-stream Retrieval-Integration (RI) model (again, only of sentence comprehension), in which syntactic and semantic processing are more integrated, does account for the data at hand (see Brouwer, 2014, for the computational details). On the RI model, N400 amplitude reflects the contextualized retrieval of the conceptual knowledge associated with an incoming word from memory while the P600 indexes the integration of the meaning of an incoming word with the unfolding utterance interpretation. Cortically, they see the retrieval processes underlying the N400 as mediated by the left posterior middle temporal gyrus and the integrative processes underlying the P600 as mediated in the left inferior temporal gyrus. 
Their model and these hypotheses set important challenges for the integrative project sketched in TA Sec.4, where the B\&S model pays more attention to the roles of dorsal and ventral streams in auditory processing, while TCG assesses the roles of dorsal and ventral streams in processing the visual context in both comprehension and production. (To date TCG says nothing about ERP data although, in Barrès, Simons, \& Arbib, 2013, we have offered synthetic event-related potentials as a computational bridge between neurolinguistic models and experiments.) While Brouwer \& Crocker note that it remains to be seen what the precise roles are that the dorsal and ventral streams play and hence if and how the MSH and the RI model can be integrated. Encouragingly, they conclude that this may be where a computational synthesis between neurolinguistics and comparative neuroprimatology is the way forward.

\subsection{Conversation and Dementia}

Wray (Wray, 2016) offers a fresh perspective on TCG. In TA, Sec.4.3.2, we used data from agrammatism to suggest that difficulties with managing the linguistic system (Grammatical Route, G, including Light Semantics, $L S$ ) are compensated for using world knowledge (Heavy Semantics, HS). Wray, on the other hand, considers persons with dementia of the Alzheimer's type. She considers scenarios where a person with dementia (PwD) asks a question, and the family carer (FC) answers it. Later, $\mathrm{PwD}$, having forgotten that the previous iteration took place, asks the question again. This brings in the dimension of time-varying shared knowledge in conversation -something that TCG work has not yet addressed but which, by modeling both comprehension and production it is well-prepared to do (whereas most neurolinguistic models focus on comprehension alone). Note the need to link to the work on conversation of Garrod \& Pickering (e.g., the broader treatment in Pickering \& Garrod, 2013, rather than the focus on turn-taking in their commentary), and assess to what extent their use of forward models reveals evolutionary challenges (pace Bornkessel-Schlesewsky et al) to the types of forward models advanced in motor control (Wolpert, Doya, \& Kawato, 2003; Wolpert \& Kawato, 1998).

Wray stresses that in dementia access to elements of world knowledge (HS) becomes unstable. Furthermore, this instability impacts not just PwD but also FC. PwD is unsure what the core interactional parameters are;. FC is unsure what PwD knows/remembers and how best to frame messages. Such interactions "can be emotionally charged and stressful ..." Note that this brings in a dimension ignored in TCG and the other models discussed here, that of emotion. Moreover, it is not the emotion conveyed as part of the meaning of an utterance, but rather emotion related to the flow (or not) of the conversation. Wray helps us see how the TCG framework can link to this consideration, but she opens up another dimension of computational comparative neuroprimatology, namely the need to understand the brain mechanisms supporting emotion both in driving individual behavior and as a vital component of social interaction (Arbib \& Fellous, 2004; Fellous \& Arbib, 2005; Jeannerod, 2005; Kelley, 2005).

The key notion for Wray in her account of PwD-FC interaction is that of unaccustomed pragmatic spaces which cannot be mended using customary strategies. These arise because the interlocutors' confidence in pinning down shared knowledge is undermined. As an attempted solution, "PwDs deploy easily-produced formulaic expressions as a tool to manage the crisis in pragmatics. However the deployment of formulaic expressions is not confined to

PwDs: they are also used in striking number by the interlocutors ... It seems that if one puts less cognitive effort into producing output, it creates a protective emotional space." 
TCG allows content words (or formulaic utterances; Wray lumps these into a single set W) to activate HS ("heavy" semantics) or LS (the "light" semantics implicit in constructions), whereas function words (unless part of a formula) can only function through their role in grammatical constructions. Wray's variation on TCG is to view certain single and multiword formulaic expressions as having a pragmatic management role involving only HS, and being ignored by LS. Unaccustomed pragmatic spaces do not arise in dementia interaction because there is anything wrong with the use of these HS-only items, but rather because it is difficult for a hearer to treat them as HS only when searching for meaning in an unstable interaction.

Here we are back to the general issue of competition/cooperation. In general there will, in normal discourse (though with occasional embarrassing exceptions) be acceptably rapid convergence to a shared interpretation. But if this takes too long, or if the result is out of synch with the current context, then - as Wray shows - this can incur an emotional cost that colors the ongoing conversation. Note that most people (unlike PwD) have a rich context model. This points us to another challenge for extending TCG - to go beyond the limited working memory or SemRep relevant to a single episode or utterance to the accumulation of "intermediate term memory" (Seifert et al., 2013).

Wray closes by discussing the holistic protolanguage model, whereby forms managed by pragmatics preceded referential lexis and grammar. She speculates that formulaic responses are a remnant of what was, before we had the full flexibility of LS and G, a primary solution to the daily challenge of sharing knowledge. The emergence of full language would have provided the mechanism for a more nuanced management of shared knowledge in normal circumstances, with the vast majority of single and multiword W tied to LS. When we deploy W in an HS-only mode, she suggests, perhaps we glimpse the power and limitations of G and LS in unpicking holistic meaningmaking. The only caveat to be stressed is that at the holophrasis stage of protolanguage, the holophrases were not formulas composed of extant words but rather unitary utterances whose decomposition awaited the future (if ever). Formulaic expressions in modern languages denature the words in the formulas so that the meaning of the formula has only vestigial relation to those of the words - a sort of devolution that we may invoke to infer a primeval state on which fractionation could operate.

\section{Turn-Taking}

To close this Response, consider an aspect of language that goes unaddressed by TA, yet is independently considered by both Garrod \& Pickering (Garrod \& Pickering, 2016) and Moulin-Frier \& Verschure, namely the crucial role of turn-taking in conversation. The reason that this provides a fitting finale is that we shall see that turntaking offers a path back to the general challenge of developing computational comparative neuroprimatology

Garrod \& Pickering see fluent turn-taking in dialogue as a possible bridge to the analysis of dual-stream processing (TA Sec.4) and the dyadic model of communicating brains (TA, Secs.1.4 and 2.2). They note that recent neuroimaging studies indicate that low frequency delta and theta band neural oscillations in auditory cortex synchronize with delta and theta band oscillations in the speech envelope and suggest that this brain-speech synchronization aids syllabic parsing and prediction of other important temporal events in the speech stream. "Crucially, the degree of synchronization in left auditory cortex is modulated by top-down signals emanating from left frontal and motor areas - a finding that implicates dorsal stream control of the synchronization and prediction 
process" (Park, Ince, Schyns, Thut, \& Gross, 2015). Here I must simply confess my own ignorance. None of my modeling looks at cortical rhythms; instead it simply looks at how interacting neural patterns can mediate vision, action and more. My major stumbling block is that global oscillations cannot themselves encode visual, motor or linguistic patterns. Rather, different patterns must be encoded by subsets of neurons breaking away from the lockstep of global synchronization. Does/how does overall synchronization enhance the information processing of these neurons? One clue might come from the methodology used in a model (Blair, Gupta, \& Zhang, 2008) of data suggesting that as a rat navigates through a familiar environment, a cell whose firing correlates with a particular place will fire in a different phase relative to the overall theta rhythm depending on whether the rat is approaching or departing from the corresponding place. Turning to the coordination of eye and hand (cf. TA, Sec.2.1), very recent data (Wong, Fabiszak, Novikov, Daw, \& Pesaran, 2016) shows that coherent neuronal ensembles are rapidly recruited when making a look-reach decision. Recorded neuronal activity in the lateral and medial banks of the intraparietal sulcus (IPS) of the posterior parietal cortex while monkeys made choices about where to look and reach revealed that ensembles of neurons that displayed coherent patterns of spiking activity extending across the IPS predicted movement choices substantially earlier than other neuronal ensembles. Here it is not the global rhythm that matters so much as coherence of spiking in a subset of neurons that encode relevant information. Such findings should help us place claims about cortical rhythms in our comparative perspective - but they also point to the need for models that pay attention to coherent firing, a feature lacking in my prior research.

Moulin-Frier \& Verschure report on a computational model, in the interacting AI agents mode, where turntaking behavior emerges in agent populations needing to maintain group cohesion for a survival purpose (e.g. because they are not adapted to survive in isolation) and living in a dense environment preventing visual contact, e.g. a dense forest as confronted by the marmoset. In this context, a way to maintain group cohesion is through the use of vocalizations to convey information about the presence and state of each group member. However, if several agents are vocalizing at the same time, these vocalizations will interfere, making agent identification harder to realize and to maintain group cohesion, consequently favoring the emergence of a turn-taking strategy.

What is most relevant here is the mention of marmoset monkeys which indeed exhibit cooperative vocal communication by taking turns, with experimental data suggesting that the behavior is learnt during infancy (Takahashi et al., 2015). Moreover, Garrod \& Pickering also discuss vocal turn-taking in marmosets, and the suggestion that this relies on coupled oscillations between the monkeys. Takahashi, Narayanan, and Ghazanfar (2012) developed a computational model based on the interactions among three neural structures (drive, motor, and auditory) with feedback connectivity inspired by published physiological and anatomical data. They fitted the model to the temporal dynamics of spontaneous vocalizations produced by isolated marmosets and then tested the model for its ability to predict the structure of vocal exchanges between two marmosets. This is a long way from the modeling of detailed interactions between parietal and premotor circuitry of the macaque described in TA Sec.2.1, but it does suggest a path for extending those models toward dyadic interaction and the auditory system. Turn-taking in the form of "duetting" is also seen in another monkey species, the geladas (Gustison, le Roux, \& Bergman, 2012; Richman, 1978). However, vocal turn-taking is not heard in macaques.

As Moulin-Frier \& Verschure note, a key element of the adaptive process in their model, which is coherent 
with the model of Takahashi et al., is the ability to distinguish between one's own and other's vocalizations. More generally, they suggest that a key feature in the emergence and stabilization of the language-ready brain is "the shared notion of self in terms of embodiment and perceptual, cognitive, action and value systems. Especially the latter would appear key since it would underpin the ability to pursue shared goals. Hence, the common frame of reference would be the mirroring of a multi-dimensional self ... rather than the ability to interpret and execute action alone." They mention a proof of concept involving communicative humanoid robots who are able to realize complex, open-ended and dynamic dyadic tasks with a human (Lallee et al., 2015), building on earlier work (Lallee \& Dominey, 2013) with Peter Dominey, the originator of DCG.

Note how the distinction between self and other requires a mechanism to augment mirror neurons. Mirror neurons recognize what an action is independent of the agent, not who performed the action. The issue here is to address what I have called (HBGL, p.145) the binding problem for mirror neurons: For mirror neurons to function properly in social interaction, not only must they be simultaneously active for multiple actions and emotions, but the brain must also bind the encoding of each action and emotion (whether self or other) to the agent who is, or appears to be, experiencing it.

With this, we are firmly back in our domain of Computational Comparative Neuroprimatology: How can we integrate our macaque models with models of turn-taking in such a way that we can use data from neuroanatomy and neurophysiology to assess how differences in the brains of macaques, marmosets and geladas (and, of course, the marmoset-gelada hybrid, the marmelada) can explain why marmosets and geladas exhibit turn-taking, whereas macaques do not. But we do so with a new appreciation of the "mosaic evolution" charted in Sec.3.4 of this Response - that different species of monkey and ape exhibit different aspects of what we discern in the languageready brain, so that we need an evolutionary theory more subtle than a simple linear progression LCA-m $\rightarrow$ LCA-c $\rightarrow H$. sapiens. With this, we may return to computational neurolinguistics with fresh insights - but also with the understanding that turn-taking is a feature of social cooperation more generally than just for language and thus (as the diverse commentaries reveal) just one feature to be considered in charting the evolution of the language-ready brain in which language is to be understood in its many linkages to the neural mechanisms supporting interactions with the physical and social world.

Acknowledgment: This material is based in part on work supported by the National Science Foundation under Grant No. 0924674 and Grant No. BCS-1343544 "INSPIRE Track 1: Action, Vision and Language, and their Brain Mechanisms in Evolutionary Relationship" (Michael A. Arbib, Principal Investigator).

\section{References}

Arbib, M.A. (1972). The Metaphorical Brain: An Introduction to Cybernetics as Artificial Intelligence and Brain Theory. New York: Wiley-Interscience.

Arbib, M.A. (2003). Rana computatrix to human language: towards a computational neuroethology of language evolution. Philos Transact A Math Phys Eng Sci, 361(1811), 2345-2379.

Arbib, M.A. (2007). How New Languages Emerge (Review of D. Lightfoot, 2006, How New Languages Emerge, Cambridge University Press). Linguist List, 18-432, Thu Feb 08 2007, http://linguistlist.org/issues/17/171250.html.

Arbib, M.A. (2012). How the Brain Got Language: The Mirror System Hypothesis. New York \& Oxford: Oxford University Press. 
Arbib, M.A. (2013). Complex Imitation and the Language-Ready Brain. Language and Cognition, 5(2-3).

Arbib, M.A. (2015). Towards a Computational Comparative Neuroprimatology: Framing the Language-Ready Brain. Physics of Life Reviews, DOI information: 10.1016/j.plrev.2015.1009.1003.

Arbib, M.A., \& Bickerton, D. (Eds.). (2010). The Emergence of Protolanguage: Holophrasis vs compositionality. Philadelphia, Amsterdam: John Benjamins Publishing Company.

Arbib, M.A., \& Bonaiuto, J.J. (2012). Multiple Levels of Spatial Organization: World Graphs and Spatial Difference Learning. Adaptive Behavior, 20(4), 287-303.

Arbib, M.A., Bonaiuto, J.J., Bornkessel-Schlesewsky, I., Kemmerer, D., MacWhinney, B., Nielsen, F.Å., \& Oztop, E. (2014). Action and language mechanisms in the brain: Data, models and neuroinformatics. Neuroinformatics, 12(1), 209-225.

Arbib, M.A., \& Bota, M. (2003). Language Evolution: Neural Homologies and Neuroinformatics. Neural Networks, $16,1237-1260$.

Arbib, M.A., \& Fellous, J. M. (2004). Emotions: from brain to robot. Trends Cogn Sci, 8(12), 554-561.

Arbib, M.A., Ganesh, V., \& Gasser, B. (2014). Dyadic Brain Modeling, Ontogenetic Ritualization of Gesture in Apes, and the Contributions of Primate Mirror Neuron Systems. Phil Trans Roy Soc B, 369 (1644), 20130414.

Arbib, M.A., \& Iriki, A. (2013). Evolving the Language- and Music-Ready Brain. In M.A. Arbib (Ed.), Language, Music, and the Brain: A Mysterious Relationship, Strüngmann Forum Reports, vol. 10 (pp. 359-375). Cambridge, MA: MIT Press.

Arbib, M.A., Liebal, K., \& Pika, S. (2008). Primate Vocalization, Gesture, and the Evolution of Human Language. Current Anthropology, 49(6), 1053-1076. doi: doi:10.1086/593015 \% http://www.journals.uchicago.edu/doi/abs/10.1086/593015

Arbib, M.A., \& Lieblich, I. (1977). Motivational learning of spatial behavior. In J. Metzler (Ed.), Systems Neuroscience (pp. 221-239). New York: Academic Press.

Arbib, M.A., Plangprasopchok, A., Bonaiuto, J.J., \& Schuler, R.E. (2014). A Neuroinformatics of Brain Modeling and its Implementation in the Brain Operation Database BODB. Neuroinformatics, 12(1), 5-26. doi: 10.1007/s12021-013-9209-y

Arbib, M.A., \& Rizzolatti, G. (1997). Neural expectations: a possible evolutionary path from manual skills to language. Communication and Cognition, 29, 393-424.

Arnold, K., \& Zuberbühler, K. (2006a). The alarm-calling system of adult male putty-nosed monkeys, Cercopithecus nictitans martini. Animal Behaviour, 72, 643-653.

Arnold, K., \& Zuberbühler, K. (2006b). Language evolution: Semantic combinations in primate calls. Nature, 441, 303.

Barrès, V., Simons, A., \& Arbib, M.A. (2013). Synthetic event-related potentials: A computational bridge between neurolinguistic models and experiments. Neural Networks, 37, 66-92. doi: http://dx.doi.org/10.1016/j.neunet.2012.09.021

Bates, E., \& MacWhinney, B. (1989). Functionalism and the competition model. The crosslinguistic study of sentence processing, 3-73.

Blair, H.T., Gupta, K., \& Zhang, K. (2008). Conversion of a phase- to a rate-coded position signal by a three-stage model of theta cells, grid cells, and place cells. Hippocampus, 18(12), 1239-1255.

Bornkessel-Schlesewsky, I., Alday, P.M., \& Schlesewsky, M. (2016). A modality-independent, neurobiological grounding for the combinatory capacity of the language-ready brain: : Comment on "Towards a computational comparative neuroprimatology: Framing the language-ready brain" by M.A. Arbib. Physics of Life Reviews.

Bornkessel-Schlesewsky, I., \& Schlesewsky, M. (2013). Reconciling time, space and function: A new dorsal-ventral stream model of sentence comprehension. Brain Lang, 125(1), 60-76. doi: http://dx.doi.org/10.1016/j.bandl.2013.01.010

Bornkessel, I., \& Schlesewsky, M. (2006). The extended argument dependency model: a neurocognitive approach to sentence comprehension across languages. Psychological Review, 113(4), 787-821.

Brouwer, H. (2014). The Electrophysiology of Language Comprehension: A Neurocomputational Model. (PhD thesis), University of Groningen.

Brouwer, H., \& Crocker, M.W. . (2016). On the Organization of the Perisylvian Cortex: Insights from the Electrophysiology of Language: Comment on "Towards a computational comparative neuroprimatology: Framing the language-ready brain" by M.A. Arbib. Physics of Life Reviews.

Brouwer, H., Fitz, H., \& Hoeks, J.C.J. (2012). Getting real about semantic illusions: rethinking the functional role of the P600 in language comprehension. Brain Research, 1446, 127-143.

Byrne, R.W., \& Russon, A.E. (1998). Learning by imitation: a hierarchical approach. Behav Brain Sci, 21(5), 667684; discussion 684-721. 
Chang, N. (2004). A computational model of comprehension-based construction acquisition Child Language Research Forum (pp. 40-49). Stanford, CA.

Colagé, I. (2016). The Cultural Evolution of Language and Brain: Comment on "Towards a computational comparative neuroprimatology: Framing the language-ready brain" by M.A. Arbib. Physics of Life Reviews.

Collier, K., Bickel, B., van Schaik, C.P., Manser, M.B., \& Townsend, S.W. (2014). Language evolution: syntax before phonology? Proceedings of the Royal Society of London B: Biological Sciences, 281(1788). doi: $10.1098 / \mathrm{rspb} .2014 .0263$

Coudé, G. (2016). On the role of emerging voluntary control of vocalization in language evolution: Comment on "Towards a computational comparative neuroprimatology: Framing the language-ready brain" by M.A. Arbib. Physics of Life Reviews.

Coudé, G., Ferrari, P.F., Rodà, F., Maranesi, M., Borelli, E., Veroni, V., . . Fogassi, L. (2011). Neurons Controlling Voluntary Vocalization in the Macaque Ventral Premotor Cortex. PLoS One, 6(11), e26822. doi: 10.1371/journal.pone.0026822

Craik, K.J.W. (1943). The Nature of Explanation. Cambridge: Cambridge University Press.

Crocker, M.W., Knoeferle, P., \& Mayberry, M.R. (2010). Situated sentence processing: The coordinated interplay account and a neurobehavioral model. Brain Lang, 112(3), 189-201. doi: http://dx.doi.org/10.1016/j.bandl.2009.03.004

Croft, W. (2001). Radical construction grammar: syntactic theory in typological perspective. Oxford: Oxford University Press.

Croft, W. (2016). What language is the language-ready brain ready for? : Comment on "Towards a computational comparative neuroprimatology: Framing the language-ready brain" by M.A. Arbib. Physics of Life Reviews.

Davidson, I. (2010). The archeology of cognitive evolution. Wiley Interdisciplinary Reviews: Cognitive Science, $l(2), 214-229$.

Dehaene, S., \& Cohen, L. (2007). Cultural Recycling of Cortical Maps. Neuron, 56(2), 384-398. doi: http://dx.doi.org/10.1016/j.neuron.2007.10.004

Dehaene, S., Pegado, Felipe, Braga, Lucia W., Ventura, Paulo, Filho, Gilberto Nunes, Jobert, Antoinette, ... Cohen, L. (2010). How Learning to Read Changes the Cortical Networks for Vision and Language. Science, 330(6009), 1359-1364. doi: 10.1126/science. 1194140

Demiris, Y., Aziz-Zadeh, L., \& Bonaiuto, J.J. (2014). Information Processing in the Mirror Neuron System in Primates and Machines. Neuroinformatics, 12(1), 63-91. doi: 10.1007/s12021-013-9200-7

Donald, M. (1997). Precis of Origins of the modern mind: Three stages in the evolution of culture and cognition. Behavioral and Brain Sciences, 16, 737-791.

Donald, M. (1998). Mimesis and the executive suite: Missing links in language evolution. In J.R. Hurford, M. Studdert-Kennedy \& C. Knight (Eds.), Approaches to the Evolution of Language: Social and Cognitive Bases (pp. 44-67). Cambridge: Cambridge University Press.

Fellous, J.-M., \& Arbib, M.A. (Eds.). (2005). Who Needs Emotions: The Brain Meets the Robot. Oxford, New York: Oxford University Press.

Fitch, W.T., \& Jarvis, E.D. (2013). Birdsong and Other Animal Models for Human Speech, Song, and Vocal Learning. In M.A. Arbib (Ed.), Language, Music and the Brain: A Mysterious Relationship. Strüngmann Forum Reports, vol. 10 (pp. 499-539). Cambridge, MA: MIT Press.

Fogassi, L., Coudé, G., \& Ferrari, P.F. (2013). The extended features of mirror neurons and the voluntary control of vocalization in the pathway to language. Language and Cognition, 5, 145-155.

Fritz, J., Mishkin, M., \& Saunders, R.C. (2005). In search of an auditory engram. PNAS, 102 (26 ), 9359-9364.

Garrod, S., \& Pickering, M.J. (2016). Dual-stream accounts bridge the gap between monkey audition and human language processing: Comment on "Towards a computational comparative neuroprimatology: Framing the language-ready brain" by M.A. Arbib. Physics of Life Reviews.

Gasser, Brad, Cartmill, Erica A, \& Arbib, Michael A. (2014). Ontogenetic ritualization of primate gesture as a case study in dyadic brain modeling. Neuroinformatics, 12(1), 93-109.

Gregory, R.L. (1969). On How so Little Information Controls so much Behavior. In C.H. Waddington (Ed.), Towards a Theoretical Biology. 2, Sketches. Edinburgh: Edinburgh University Press.

Gustison, M.L, le Roux, A., \& Bergman, T.J. (2012). Derived vocalizations of geladas (Theropithecus gelada) and the evolution of vocal complexity in primates. Philosophical Transactions of the Royal Society of London B: Biological Sciences, 367(1597), 1847-1859.

Hawkins, J.A. (2016). The emergence of grammar in a language-ready brain: Comment on "Towards a computational comparative neuroprimatology: framing the language-ready brain" by M.A. Arbib. Physics of Life Reviews. 
Hecht, E.E. (2016). Adaptations to vision-for-action in primate brain evolution: Comment on "Towards a Computational Comparative Neuroprimatology: Framing the Language-Ready Brain” by M.A. Arbib. Physics of Life Reviews.

Hecht, E.E., Gutman, D.A., Khreisheh, N., Taylor, S.V., Kilner, J., Faisal, A.A., . . Stout, D. (2015). Acquisition of Paleolithic toolmaking abilities involves structural remodeling to inferior frontoparietal regions. Brain Structure and Function, 220(4), 2315-2331. doi: 10.1007/s00429-014-0789-6

Heine, B. (2016). On the role of context in language evolution: : Comment on "Towards a computational comparative neuroprimatology: Framing the language-ready brain" by M.A. Arbib. Physics of Life Reviews.

Heine, B., Claudi, U., \& Hünnemeyer, F. (1991). Grammaticalization: a conceptual framework. Chicago: University of Chicago Press.

Hihara, S., Yamada, H., Iriki, A., \& Okanoya, K. (2003). Spontaneous vocal differentiation of coo-calls for tools and food in Japanese monkeys. Neuroscience Research, 45, 383-389.

Hill, J.C. (1983). A computational model of language acquisition in the two-year-old. Cognition and Brain Theory, 6, 287-317.

Iriki, A. (2006). The neural origins and implications of imitation, mirror neurons and tool use. Current Opinion in Neurobiology, 16(6), 660-667.

Iriki, A. (2016). Ready...., Set, Go!! : Comment on "Towards a computational comparative neuroprimatology: Framing the language-ready brain" by M.A. Arbib. Physics of Life Reviews.

Iriki, A., \& Taoka, M. (2012). Triadic (ecological, neural, cognitive) niche construction: a scenario of human brain evolution extrapolating tool use and language from the control of reaching actions. Philosophical Transactions of the Royal Society B: Biological Sciences, 367, 10-23

Ishibashi, H., Hihara, S., Takahashi, M., Heike, T., Yokota, T., \& Iriki, A. (2002). Tool-use learning induces BDNF expression in a selective portion of monkey anterior parietal cortex. Brain Res Mol Brain Res, 102(1-2), 110112.

Jeannerod, M. (2005). How do we decipher others' minds? In J.-M. Fellous \& M.A. Arbib (Eds.), Who Needs Emotions: The Brain Meets the Robot (pp. 147-169). Oxford, New York: Oxford University Press.

Kato, M., Okanoya, K., Koike, T., Sasaki, E., Okano, H., Watanabe, S., \& Iriki, A. (2014). Human speech-and reading-related genes display partially overlapping expression patterns in the marmoset brain. Brain Lang, 133, 26-38.

Kelley, A.E. (2005). Neurochemical Networks Encoding Emotion and Motivation: An Evolutionary Perspective. In J.-M. Fellous \& M.A. Arbib (Eds.), Who Needs Emotions: The Brain Meets the Robot (pp. 29-77). Oxford, New York: Oxford University Press.

Knoeferle, P. (2016). Challenges and insights for situated language processing: Comment on "Towards a computational comparative neuroprimatology: Framing the language-ready brain" by M.A. Arbib. Physics of Life Reviews.

Knoeferle, P., \& Crocker, M.W. (2006). The Coordinated Interplay of Scene, Utterance, and World Knowledge: Evidence From Eye Tracking. Cognitive Science, 30 481-529.

Kumashiro, M., Ishibashi, H., Uchiyama, Y., Itakura, S., Murata, A., \& Iriki, A. (2003). Natural imitation induced by joint attention in Japanese monkeys. Int J Psychophysiol, 50, 81-99.

Laland, Kevin N., Odling-Smee, John, \& Feldman, Marcus W. (2000). Niche construction, biological evolution, and cultural change. Behavioral and Brain Sciences, 23(01), 131-146. doi: doi:10.1017/S0140525X00002417

Lallee, S., \& Dominey, P.F. (2013). Multi-modal convergence maps: from body schema and self-representation to mental imagery. Adaptive Behavior, 21(4), 274-285. doi: 10.1177/1059712313488423

Lallee, S., Vouloutsi, V., Munoz Maria, B., Grechuta, K., Llobet Jordi-Ysard, P., Sarda, M., \& P.F.M.J., Verschure. (2015). Towards the synthetic self: making others perceive me as an other Paladyn, Journal of Behavioral Robotics (Vol. 6).

Liebal, K. (2016). The ontogeny of great ape gesture - not a simple story: Comment on "Towards a computational comparative neuroprimatology: Framing the language-ready brain" by M.A. Arbib. Physics of Life Reviews.

MacWhinney, B. (1987). The Competition Model. In B. MacWhinney (Ed.), Mechanisms of language acquisition (pp. 249-308). Hillsdale, NJ: Lawrence Erlbaum.

MacWhinney, B. (2010). Computational models of child language learning: an introduction. J. Child Lang., 37, 477485.

MacWhinney, B. (2012). Item-based patterns in early syntactic development. In T. Herbst (Ed.), Valency relations. Berlin: Springer.

Minsky, M.L. (1965). Matter, Mind and Models Information Processing 1965, Proceedings of IFIP Congress 65, Vol.1 (pp. 45-59). Washington, DC: Spartan Books. 
Moulin-Frier, C., \& Arbib, M.A. (2013). Recognizing Speech in a Novel Accent: The Motor Theory of Speech Perception Reframed. Submitted for publication, 107(4), 421-447.

Moulin-Frier, C., \& Verschure, P.F.M.J. (2016). Two possible driving forces supporting the evolution of animal communication: Comment on "Towards a computational comparative neuroprimatology: Framing the languageready brain" by M.A. Arbib. Physics of Life Reviews.

O'Keefe, J. (1996). The spatial prepositions in English, vector grammar, and the cognitive map theory. In P. Bloom, M. Peterson, L. Nadel \& M. Garrett (Eds.), Language and space (pp. 277-316). Cambridge, MA: MIT Press.

O'Keefe, J. (2003). Vector grammar, places, and the functional role of the spatial prepositions in English. In E.van der Zee \& J. Slack (Eds.), Representing Direction in Language and Space (pp. 69-85). Oxford: Oxford University Press.

O'Keefe, J. (2014). Spatial Cells in the Hippocampal Formation. Nobel Lecture on 7 December 2014 at Aula Medica, Karolinska Institutet in Stockholm, http://www.nobelprize.org/mediaplayer/index.php?id=2413.

Oztop, E., Kawato, M., \& Arbib, M.A. (2013). Mirror neurons: Functions, mechanisms and models. Neuroscience Letters, 540 43-55. doi: http://dx.doi.org/10.1016/j.neulet.2012.10.005

Park, H., Ince, R.A.A., Schyns, P.G., Thut, G., \& Gross, J. (2015). Frontal Top-Down Signals Increase Coupling of Auditory Low-Frequency Oscillations to Continuous Speech in Human Listeners. Current Biology, 25(12), 1649-1653. doi: http://dx.doi.org/10.1016/j.cub.2015.04.049

Pickering, M.J., \& Garrod, S. (2013). An Integrated Theory of Language Production and Comprehension. Behavioral and Brain Sciences, 36(4), 329-347.

Quallo, M. M., Price, C. J., Ueno, K., Asamizuya, T., Cheng, K., Lemon, R. N., \& Iriki, a. (2009). Gray and white matter changes associated with tool-use learning in macaque monkeys. Proc Natl Acad Sci U S A, 106(43), 18379-18384. doi: 10.1073/pnas.0909751106

Richman, B. (1978). The synchronization of voices by gelada monkeys. Primates, 19(3), 569-581.

Rilling, J.K., Glasser, M.F., Preuss, T.M., Ma, X., Zhao, T., Hu, X., \& Behrens, T.E. (2008). The evolution of the arcuate fasciculus revealed with comparative DTI. Nature Neuroscience, 11(4), 426-428.

Rizzolatti, G., \& Arbib, M. A. (1998). Language within our grasp. Trends in Neurosciences, 21(5), 188-194.

Russon, A. (2016). Reconsidering great ape imitation and pantomime: Comment on "Towards a computational comparative neuroprimatology: Framing the language-ready brain" by M.A. Arbib. Physics of Life Reviews.

Sandler, W., Aronoff, M., Meir, I., \& Padden, C. (2011). The gradual emergence of phonological form in a new language. Natural Language \& Linguistic Theory, DOI: 10.1007/s11049-11011-19128-11042.

Schwartz, J.-L., M.-L., Barnaud, Bessiere, P., Diard, J., \& Moulin-Frier, C. (2016). Phonology in the mirror: Comment on "Towards a computational comparative neuroprimatology: Framing the language-ready brain" by M.A. Arbib. Physics of Life Reviews.

Seifert, U., Verschure, P.F.M.J., Arbib, M.A., Cohen, A.J., Fogassi, L., Fritz, T., . . Scherer, K. (2013). Semantics of Internal and External Worlds. In M.A. Arbib (Ed.), Language, Music, and the Brain: A Mysterious Relationship, Strüngmann Forum Reports, vol. 10. Cambridge, MA: MIT Press.

Sinha, C. (2013). Niche construction, too, unifies praxis and symbolization. Language and Cognition, 5(2-3), 261271.

Steels, L. (2011). Modeling the cultural evolution of language. Physics of Life Reviews, 8(4), 339-356.

Steels, L. (2016). I'm gonna have to science the shit out of this. What a language-ready brain needs to deal with actual language use: : Comment on "Towards a computational comparative neuroprimatology: Framing the language-ready brain" by M.A. Arbib. Physics of Life Reviews.

Stout, D. (2016). The modern era of research on language evolution: moving forward: Comment on "Towards a computational comparative neuroprimatology: Framing the language-ready brain" by M.A. Arbib. Physics of Life Reviews.

Stout, D., \& Chaminade, T. (2012). Stone tools, language and the brain in human evolution. Philosophical Transactions of the Royal Society B: Biological Sciences, 367(1585), 75-87. doi: 10.1098/rstb.2011.0099

Takahashi, D.Y., Fenley, A.R., Teramoto, Y., Narayanan, D.Z, Borjon, J.I., Holmes, P., \& Ghazanfar, A.A... (2015). The developmental dynamics of marmoset monkey vocal production. Science, 349(6249), 734-738.

Takahashi, D.Y., Narayanan, D., \& Ghazanfar, A.A. (2012, 7-9 Nov. 2012). A computational model for vocal exchange dynamics and their development in marmoset monkeys. Paper presented at the 2012 IEEE International Conference on Development and Learning and Epigenetic Robotics (ICDL).

Tennie, C., Call, J., \& Tomasello, M. (2009). Ratcheting up the ratchet: on the evolution of cumulative culture. Philos Trans R Soc Lond B Biol Sci, 364(1528), 2405-2415.

Tomasello, M., \& Call, J. (1997). Primate Cognition. New York: Oxford University Press. 
Visalberghi, E., Fragaszy, D., Ottoni, E., Izar, P., de Oliveira, M. G., \& Andrade, F. R. (2007). Characteristics of hammer stones and anvils used by wild bearded capuchin monkeys (Cebus libidinosus) to crack open palm nuts. Am J Phys Anthropol, 132(3), 426-444.

Visalberghi, E., Savage-Rumbaugh, E. S., \& Fragaszy, D. M. (1995). Performance in a tool-using task by common chimpanzees (Pan troglodytes), bonobos (Pan paniscus), an orang utan (Pongo pygmaeus) and capuchin monkeys (Cebus apella). Journal of Comparative Psychology, 109(1), 52-60.

Wilkins, W., \& Wakefield, J. (1995). Brain evolution and neurolinguistic preconditions. Brain and Behavioral Science, 18, 161-226.

Wolpert, D.M., Doya, K., \& Kawato, M. (2003). A unifying computational framework for motor control and social interaction. Philosophical Transactions of the Royal Society of London. Series B: Biological Sciences, 358(1431), 593-602. doi: 10.1098/rstb.2002.1238

Wolpert, D.M., \& Kawato, M. (1998). Multiple paired forward and inverse models for motor control. Neural Networks, 11(7-8), 1317-1329.

Wong, Y.T., Fabiszak, M.M., Novikov, Y., Daw, N.D., \& Pesaran, B. (2016). Coherent neuronal ensembles are rapidly recruited when making a look-reach decision. [Article]. Nat Neurosci, 19(2), 327-334. doi: $10.1038 / \mathrm{nn} .4210$

http://www.nature.com/neuro/journal/v19/n2/abs/nn.4210.html\#supplementary-information

Wray, A. (2016). Accommodating 'unaccustomed pragmatic spaces' in Arbib's model: Comment on "Towards a computational comparative neuroprimatology: Framing the language-ready brain” by M.A. Arbib. Physics of Life Reviews.

Yamazaki, Y., Echigo, C., Saiki, M., Inada, M., Watanabe, S., \& Iriki, A. (2011). Tool-use learning by common marmosets (Callithrix jacchus). Experimental Brain Research, 213(1), 63-71.

Yoshida, K., Saito, N., Iriki, A., \& Isoda, M. (2011). Representation of others' action by neurons in monkey medial frontal cortex. Current biology, 21(3), 249-253. doi: 10.1016/j.cub.2011.01.004 